\title{
The Human Genome Project, and recent advances in personalized genomics
}

\author{
This article was published in the following Dove Press journal: \\ Risk Management and Healthcare Policy \\ 16 February 2015 \\ Number of times this article has been viewed
}

\author{
Brenda J Wilson \\ Stuart G Nicholls \\ Department of Epidemiology and \\ Community Medicine, Faculty of \\ Medicine, University of Ottawa, \\ Ottawa, ON, Canada
}

Correspondence: Brenda J Wilson Department of Epidemiology and Community Medicine, Faculty of Medicine, University of Ottawa, 45I Smyth Road, RGN 3230E

Ottawa, ON KIH 8M5, Canada

$\mathrm{Tel}+|6| 35625800$ ext $826 \mid$

$\mathrm{Fax}+\mathrm{I} 6135625465$

Email bwilson@uottawa.ca

\begin{abstract}
The language of "personalized medicine" and "personal genomics" has now entered the common lexicon. The idea of personalized medicine is the integration of genomic risk assessment alongside other clinical investigations. Consistent with this approach, testing is delivered by health care professionals who are not medical geneticists, and where results represent risks, as opposed to clinical diagnosis of disease, to be interpreted alongside the entirety of a patient's health and medical data. In this review we consider the evidence concerning the application of such personalized genomics within the context of population screening, and potential implications that arise from this. We highlight two general approaches which illustrate potential uses of genomic information in screening. The first is a narrowly targeted approach in which genetic profiling is linked with standard population-based screening for diseases; the second is a broader targeting of variants associated with multiple single gene disorders, performed opportunistically on patients being investigated for unrelated conditions. In doing so we consider the organization and evaluation of tests and services, the challenge of interpretation with less targeted testing, professional confidence, barriers in practice, and education needs. We conclude by discussing several issues pertinent to health policy, namely: avoiding the conflation of genetics with biological determinism, resisting the "technological imperative", due consideration of the organization of screening services, the need for professional education, as well as informed decision making and public understanding.
\end{abstract}

Keywords: genomics, personalized medicine, ethics, population health, evidence, education

\section{Introduction}

The publication of the first sequence of the human genome is regarded as one of the major landmarks in modern biological research. The Human Genome Project represented the collective efforts of scientists in many countries, funded through public programs and private enterprise. The first sequence took 13 years to accomplish; ${ }^{1}$ not much more than a decade later, next generation sequencing (NGS) technologies - including whole genome or exome sequencing (WGS/WES) - are becoming increasingly available in many hospital laboratories, with a number of published case studies in North America and Europe. ${ }^{2-8}$ The " $\$ 1,000$ genome" is more or less here. ${ }^{1}$ Major public bodies are currently supporting exploratory initiatives which integrate NGS into aspects of routine clinical care. For example, in the US, the National Institutes of Health have funded three projects examining the use of NGS as part of established newborn screening programs; ${ }^{9}$ and, in the UK, a major publicly-funded initiative aims to sequence the genomes of 100,000 patients, with a view to learning "new medical insights" and "bring benefits to patients". ${ }^{10}$ 
These technological advances have been accompanied by claims that we are on the cusp of a paradigm shift to an age of personalized medicine that “... uses an individual's genetic profile to guide decisions made in regard to prevention, diagnosis, and treatment of disease." 11 This is a profound shift in thinking from genetics as a specialist interest addressing rare disorders to the use of genetic information in all aspects of health care. The purpose of this review is to discuss proposals for using genomic approaches in population screening contexts, to describe the current challenges and evidence gaps, and to suggest priorities for public policy and practice.

\section{From clinical genetics to personalized medicine}

The focus of traditional clinical genetics has been on identifying monogenic disorders, often pre-specified on the basis of a person's family history, ethnicity, or medical history. These variants - mutations - are usually of high penetrance, ie, carrying the mutation is associated with a high likelihood of developing the disorder in question. The family history may point to dominant, recessive, $\mathrm{X}$-linked, or some other form of single gene (monogenic), Mendelian inheritance.

In terms of service organization and culture, medical genetics departments are generally specialist units, often located in tertiary care facilities, sometimes linked with dedicated testing laboratories, and staffed by medical genetics specialists and formally trained genetic counselors. Patients are usually referred on the basis of an unusual family history, birth of a child with a serious congenital anomaly, or diagnosis of a suspected genetic condition. Genetic assessment is a painstaking process, of which comprehensive family history collection is a central activity. Genetic counseling also includes assessment of patients' information and emotional needs, and - because the balance of benefits and harms is highly individualized - is usually non-directive.

In contrast, personalized medicine is conceived as more broadly applicable across health care. It includes the strategy of genetic profiling to offer individual risk information for multifactorial disorders (eg, cardiovascular disease, ${ }^{12}$ cancers, ${ }^{13}$ and type 2 diabetes ${ }^{14}$ ), where disease risk results from interaction between several genes (polygenic) as well as non-genomic factors. Genetic profiling often involves measuring single nucleotide polymorphisms (SNPs): variations in the smallest building blocks of DNA. ${ }^{15}$ While SNPs may lead to mutations that cause monogenic disorders (which are generally rare, usually sufficient in themselves to cause disease, and are more readily identifiable as causative), ${ }^{16}$ SNPs associated with more common, complex diseases, generally convey only minor excess risk ${ }^{17}$ making them more difficult to identify when embedded within a background of widespread non-pathogenic variation across the genome. ${ }^{16}$

Genetic profiling may be narrowly targeted, using defined panels of SNPs designed to provide risk information for a specific health condition (eg, colorectal cancer), or may be less targeted, with SNP-based genome-wide profiling addressing multiple disorders. ${ }^{18}$ Least targeted are those approaches that use NGS technologies to provide "complete" genomic information on an individual. ${ }^{19}$ Thus, the scope of "personalized medicine" may range from targeted testing of one or several mutations associated with rare monogenic, high penetrance disorders at one extreme to, at the other, sequencing a patient's exome or genome without targeting specific variants.

Ultimately, the service model underpinning the delivery of personalized medicine is that of "genomics in medicine"the integration of genomic testing with other clinical investigations, delivered by health care professionals who are not medical geneticists, and where a positive test result does not imply a serious genetic diagnosis, rather is interpreted alongside the entirety of a patient's health and medical data.

\section{Prospects for population screening}

Screening is the "systematic, proactive offer [of a test] to members of a certain group of individuals". ${ }^{20}$ This differs distinctly from clinical genetics in that the application of the screening test is not initially pre-specified on the basis of a person's family or medical history. The goal of screening is disease detection at an early or precursor phase, where intervention may alter natural history. The orientation of personalized medicine approaches to identifying individual disease susceptibility has opened up discussion of the possible benefits of using genomic information to improve existing population screening programs. ${ }^{20-24}$

Genetic information already forms the basis for many screening tests applied to asymptomatic individuals, using direct DNA-based methods or phenotypic markers (eg, biochemical) of genetic or chromosomal conditions (Table 1). These fit largely within the model of traditional genetics services, and some genetic screening programs have been available for over 30 years. Examples include antenatal screening for major chromosomal anomalies, ${ }^{25}$ newborn screening for serious genetic disorders, ${ }^{26,27}$ family-based cascade screening of first and second degree relatives of individuals diagnosed with genetic conditions, ${ }^{20,25,28}$ and carrier screening of targeted population groups to inform reproductive planning or early disease detection..$^{27,29}$ 
Table I Genetic screening interventions

\begin{tabular}{|c|c|c|}
\hline $\begin{array}{l}\text { Screening } \\
\text { intervention }\end{array}$ & Target population & $\begin{array}{l}\text { Example } \\
\text { conditions }\end{array}$ \\
\hline \multicolumn{3}{|l|}{ Currently available } \\
\hline $\begin{array}{l}\text { Pre-conceptional } \\
\text { screening }\end{array}$ & $\begin{array}{l}\text { Individuals planning } \\
\text { pregnancy }\end{array}$ & $\begin{array}{l}\text { Recessive conditions, } \\
\text { eg, cystic fibrosis }\end{array}$ \\
\hline Antenatal screening & Pregnant individuals & $\begin{array}{l}\text { Major chromosomal } \\
\text { anomalies, eg, Down } \\
\text { syndrome }\end{array}$ \\
\hline Newborn screening & Neonates & $\begin{array}{l}\text { Inborn errors of } \\
\text { metabolism, eg, } \\
\text { phenylketonuria }\end{array}$ \\
\hline Cascade screening & $\begin{array}{l}\text { First and second degree } \\
\text { relatives of individual } \\
\text { with genetic disorder }\end{array}$ & $\begin{array}{l}\text { Recessive conditions, } \\
\text { eg, familial } \\
\text { hypercholesterolemia }\end{array}$ \\
\hline $\begin{array}{l}\text { Population carrier } \\
\text { screening }\end{array}$ & $\begin{array}{l}\text { Defined population } \\
\text { subgroups }\end{array}$ & $\begin{array}{l}\text { Genetic conditions } \\
\text { with high prevalence } \\
\text { in subgroup, eg, } \\
\text { hemoglobinopathies }\end{array}$ \\
\hline $\begin{array}{l}\text { Direct-to- } \\
\text { consumer tests }\end{array}$ & $\begin{array}{l}\text { Individuals willing } \\
\text { to purchase }\end{array}$ & $\begin{array}{l}\text { Common disease } \\
\text { susceptibility, eg, } \\
\text { cardiovascular disease }\end{array}$ \\
\hline \multicolumn{3}{|c|}{ Potential/in development } \\
\hline $\begin{array}{l}\text { Disease-based } \\
\text { case finding }\end{array}$ & $\begin{array}{l}\text { Patients with common } \\
\text { serious conditions }\end{array}$ & $\begin{array}{l}\text { Common conditions } \\
\text { with genetic subtypes, } \\
\text { eg, some cancers }\end{array}$ \\
\hline $\begin{array}{l}\text { Personalized/ } \\
\text { stratified population } \\
\text { screening }\end{array}$ & $\begin{array}{l}\text { Target population for } \\
\text { standard (non-genetic) } \\
\text { screening }\end{array}$ & $\begin{array}{l}\text { Conditions screened } \\
\text { for at population } \\
\text { level, eg, colorectal } \\
\text { cancer }\end{array}$ \\
\hline $\begin{array}{l}\text { Case finding in } \\
\text { whole genome/ } \\
\text { exome sequencing }\end{array}$ & $\begin{array}{l}\text { Patients undergoing } \\
\text { whole genome/exome } \\
\text { sequencing for clinical } \\
\text { diagnostic investigation }\end{array}$ & $\begin{array}{l}\text { Rare "actionable" } \\
\text { genetic mutations, eg, } \\
\text { retinoblastoma }\end{array}$ \\
\hline
\end{tabular}

New strategies for identifying sub-groups of patients with monogenic versions of common serious disorders are being evaluated, blurring the boundary between diagnostic investigation and targeted screening. For example, while it is currently not feasible to test all breast cancer patients for genetic susceptibility (although this has recently been proposed) ${ }^{30}$ specific tumor phenotypes (eg, receptor status) may provide a clue to genetic etiology, and prompt germline mutation testing in the patient. ${ }^{31}$ A positive BRCA1/2 test would do more than explain an existing diagnosis: the patient would be at risk of a second breast cancer, malignancies in other organs, and might benefit from altered management and surveillance. The result would also alert clinicians to the importance of offering at-risk relatives genetic counseling and mutation testing, if appropriate.

For reasons of space, we do not discuss further these approaches described above. Neither do we discuss family history as a form of personalized medicine (we direct readers toward other reviews which cover this topic comprehensively), ${ }^{32,33}$ nor developments in direct to consumer availability of genetic tests (a complex topic that merits an article in its own right). ${ }^{34-37}$ The main focus of this article is on emerging prospects for personalizing screening, specifically two general approaches that illustrate recent thinking about how genetic information may be used in screening. The first is a narrowly targeted approach in which genetic profiling is linked with standard populationbased screening for single disorders; the second is broader assessment of variants associated with multiple single gene disorders, performed opportunistically on patients being investigated for unrelated conditions.

\section{Personalized screening}

Population screening involves the offer of a test to a target population, for the purpose of disease (or pre-disease) detection at a sufficiently early stage for interventions to reduce mortality and/or morbidity. The principle of risk stratification is already universally embedded in population screening approaches, in the form of age-based eligibility criteria. Age is an easily applied individual attribute, and is a way of operationalizing a risk threshold where screening is considered worthwhile, because of a favorable balance of harms, benefits, and cost to society. For example, the risk threshold used by the UK National Breast Screening Programme is a 10 year absolute risk of $\geq 2.5 \%$; this translates to age eligibility of 47-73 years. ${ }^{22}$ However, even honing down on a population group exceeding an age-based risk threshold, it is inevitable that all population-based screening programs experience an unavoidable rate of false positive and false negative screen results.

A number of groups have explored the use of targeted genetic profiling as a way of increasing the accuracy of risk stratification. Setting aside the rare monogenic forms of usually complex disorders, individual genetic variants generally confer only a small increase in individual disease risk, and even panels with multiple variants are poor at discriminating disease risk in individuals. ${ }^{38}$ However, when combined with age, genetic panels may offer more accurate risk stratification and indicate more tailored approaches to the timing or intensity of screening tests (so-called "personalized screening"). For example, for individuals in a highest risk stratum, surveillance might begin at a younger age or screening frequency shortened; while individuals in lower risk strata might benefit from a reduction in screening intensity.

Pashayan et $\mathrm{al}^{39}$ model this approach using the UK National Breast Screening Programme as a case study. They use as an example a panel of 67 common SNPs that explain 
approximately $14 \%$ of the genetic component of breast cancer risk. They calculate that profiling using this panel plus age would lead to some women as young as 35 , and some as old as 79 , being offered screening because they reach the threshold of $2.5 \% 10$ year absolute risk; conversely, 24\% fewer women aged 47-73 would be reclassified below the risk threshold and therefore not offered screening. ${ }^{39}$ Overall, $3 \%$ fewer cases would be detected (lower sensitivity), but there would be a lower rate of false positive screens (higher specificity). If this group's analyses are valid, the addition of targeted genetic profiling would potentially lead to some missed cancers, a reduction in unnecessary diagnostic investigations, a higher detection rate of (predicted to be more aggressive) ${ }^{40}$ cancers in younger individuals, and reduction in over-diagnosis of indolent or latent cancers. Similar arguments have been proposed for screening for colorectal cancer $^{41,42}$ and prostate cancer. $^{39}$

Genetic profiling for stratification of population-based screening must be formally evaluated. ${ }^{24,39,43,44}$ Predictions about risk reclassification, disease detection, and changing eligibility for screening need to be confirmed in empirical studies in representative populations, and randomized controlled trials comparing personalized screening with current approaches would allow quantification of benefits, harms, and costs in actual practice. While it is anticipated that personalized screening would reduce negative psychosocial impacts of screening, there are multiple issues which would need to be taken into account (discussed below) before genetic profiling could be considered for widespread implementation.

\section{Opportunistic screening as part of WGS/WES}

The second emerging pattern for genome-based screening is linked to the increasing application of NGS technologies (sequencing and associated bioinformatics capabilities) as clinical tools. This has become possible as their costs fall and their application in clinical settings has been boosted by major research funding, particularly in the US. ${ }^{45}$ The earliest areas of clinical exploration and application have been in the investigation of rare disorders which elude standard genetic diagnostic approaches, the individualization of cancer treatment, ${ }^{46}$ and prenatal/preconception screening and preventive health assessment. ${ }^{47,48}$ Having sequenced an individual's entire genome or exome during the course of clinical investigation, it is a short step to interrogating it for variants with known or suspected pathogenic potential as a form of opportunistic screening, unrelated to the original clinical indication. This screening approach has been most notably supported by the American College of Medical Genetics and Genomics; this professional body published recommendations which listed 57 genetic variants related to 24 conditions that should be reported for every patient undergoing WGS/WES. ${ }^{49}$ The recommendations refer to these variants as "incidental", and define them as "the results of a deliberate search for pathogenic or likely pathogenic alterations in genes that are not apparently relevant to a diagnostic indication for which the sequencing test was ordered". ${ }^{49}$ The variants are generally associated with rare single gene disorders, and were selected by expert consensus as representing conditions which are "clinically actionable", ie, for which confirmatory diagnostic approaches are usually available; where preventive or treatment interventions are usually available; and where there is usually a long pre-symptomatic period. Examples include genes associated with hereditary breast and ovarian cancer, retinoblastoma, neurofibromatosis, and several cardiomyopathies (for a full list, please refer to Green et $\mathrm{al}^{49}$ ). The recommendations suggest that only around $1 \%$ of sequencing reports would be expected to include incidental variant information, ${ }^{50}$ and the clinician ordering the sequencing for the initial indication would be responsible for interpreting the significance of results in the light of the patient's complete clinical information, disclosing the findings appropriately, and advising patients on appropriate clinical management. ${ }^{26,51}$

While these recommendations will inevitably evolve as knowledge accumulates, the underlying approach of opportunistic screening to find undiagnosed cases is one familiar to public health practice. The proponents for this targeted genetic screening approach point to benefits in disease prevention, prompt treatment, informed reproductive planning, and cascade testing of at-risk relatives. ${ }^{49}$ However, the recommendations have attracted considerable criticism that the evidence base is lacking for many of the assumptions, particularly the possibilities for false positives. ${ }^{52}$ Some of the challenges are discussed below.

\section{Challenges to genomic approaches to screening Inadequate evidence base}

Many observers assert that, to date, there is inadequate empirical evidence available to support informed policy decisions about the use of genetic profiling in personalized screening, or of opportunistic screening as part of WGS/WES. The most helpful evidence for policy making relates to effectiveness in practice, compared with standard of care (also referred to as "clinical utility"). ${ }^{53}$ The overall utility of a genetic approach 
to screening depends on how processes of care are altered, such as alteration in personal or clinical decision making, and the effectiveness of preventive or therapeutic interventions which flow from these decisions. The ultimate test of clinical utility is the impact on patient health outcomes, including changes in morbidity and mortality of the target condition, and also positive and negative psychosocial outcomes such as changes in personal risk perception, emotional impacts of risk information, and benefits from minimizing diagnostic delay, etc. ${ }^{53,54}$ Randomized controlled trials, and decision analytic modeling, addressing the range of relevant outcomes and incorporating the effect of downstream interventions form the core approaches to estimating clinical utility. ${ }^{55}$

However, in relation to personalized screening and opportunistic screening allied with NGS, the major evidence challenges at present relate to analytic and clinical validity (Table 2). Analytic validity refers to the technical performance of a test: ${ }^{56}$ how accurately and reliably the laboratory assay measures the variant in question. The primary metrics are analytic sensitivity - a positive test result when the variant in question is known to be present - and analytic specificity - a negative test result when the variant is known to be absent, ${ }^{18,56}$ but also includes evaluations of assay robustness and laboratory quality control. ${ }^{20}$ For personalized screening, confidence in a negative result is dependent on the completeness of the variants included in a panel in relation to the target population. ${ }^{57}$ Panels with an inadequate number

Table 2 Framework for evaluating genetic tests

\begin{tabular}{ll}
\hline Components and definitions & Measures \\
\hline Analytic validity & Analytic sensitivity and specificity \\
Ability to accurately and reliably & Laboratory quality control \\
measure genotype of interest & Assay robustness \\
Clinical validity & Clinical sensitivity and specificity \\
Ability to detect or predict & Prevalence of disorder \\
disorder of interest & Test positive and negative \\
& predictive value \\
& Penetrance \\
Clinical utility & Modifiers \\
Risks and benefits when & Natural history of condition \\
used in routine practice & Availability and effectiveness \\
& of treatment or preventive \\
& interventions \\
& Education \\
Ethical, legal, and social issues & Economic evaluation \\
Cross-cutting factors which & Monitoring and evaluation \\
influence all aspects of test & Stigmatization, discrimination, \\
in practice & privacy/confidentiality, family/ \\
& social issues \\
& Consent, ownership of data/ \\
\hline
\end{tabular}

Note: Data from..$^{57}$ of variants will have low sensitivity, with the possibility of erroneous re-classification of some individuals to lower risk strata. $^{58}$

For opportunistic screening performed as part of NGS, analytic validity depends on the "depth of read" provided by sequencing platforms; that is how many times a nucleotide is read during the sequencing process. Higher read depth will provide greater coverage, but higher costs. Lower coverage may decrease costs but may provide only lower confidence in the observed variants. As such, there is a compromise with respect to cost-effectiveness of different depths of read. Early work indicates considerable variation in genotype accuracy depending on the specific technique used. ${ }^{59}$ One study which focused specifically on the American College of Medical Genetics and Genomics' recommendations noted that two different sequencing platforms failed to cover $9 \%-17 \%$ of the listed variants. ${ }^{60,61}$ This suggests the possibility for false negatives, leading to difficulties in interpreting the meaning of "normal" screening results.

In the context of genetics, clinical validity refers to the ability of a test to accurately predict the trait or condition in question, or stratify future disease risk or prognosis. In personalized medicine, this must be considered in comparison with standard non-genomic approaches such as routine biochemical tests, clinical or physical measurements, etc. The metrics of clinical validity are also those of test evaluation (sensitivity, specificity, positive and negative predictive value, and area under the receiver-operator characteristics curve), and meaningful evaluation must take account of the target population and comparison with standard (non-genetic) risk prediction models. ${ }^{24,56}$

For personalized screening, the first evidence challenge is in selecting, from the considerable literature on gene-disease associations, those variants for which the association has been validated, and which offer useful independent information when incorporated into a screening panel. Initial evaluations that suggested that only a few variants might be necessary to explain a large proportion of the population risk for a complex disorder appear to be over-optimistic. ${ }^{62-64} \mathrm{We}$ have offered the example of a panel with 67 variants for breast cancer risk above; for colorectal cancer, some authors have estimated that in excess of 100 variants would be required to achieve acceptable classification accuracy ${ }^{65}$ Initiatives such as the Evaluation of Genomic Applications in Practice and Prevention group have reviewed gene panels for conditions such as cardiovascular disease, type 2 diabetes, and ovarian cancer ${ }^{56,66-68}$ and concluded insufficient evidence to make recommendations for clinical application. This work has 
been continued by the US Centers for Disease Control, which maintains a list of genomic tests grouped by evidence supporting their use. ${ }^{69,70}$

For opportunistic screening associated with NGS, the concern is one of interpretability: what is the evidence that a presumed pathogenic mutation will cause significant disease in the person's lifetime? Several studies have suggested that up to two thirds of so-called disease-causing mutations found within the Human Gene Mutation Database ${ }^{71,72}$ may be misclassified and carry lower or no clinically meaningful pathogenicity. ${ }^{61,73,74}$ Work is needed to curate and validate existing data on identified mutations in order to better characterize them, especially those classed as "variants of unknown significance", ${ }^{58}$ In addition, our understanding of the natural history of risk associated with many apparently well understood variants is increasingly challenged. It may be possible to extrapolate from experience with expanded newborn screening panels. As many (genetic) inborn errors of metabolism are now detected through biochemical screening in the neonatal period instead of through clinical symptoms presenting in later infancy or childhood, the apparent prevalence for some conditions appears to have risen. ${ }^{75,76}$ It is becoming evident that some "pathogenic" genotypes may actually be associated with a wider range of phenotypes, including asymptomatic and milder forms of disease. ${ }^{76}$ There is concern about over-diagnosis and overtreatment of some individuals resulting from the "genetic diagnosis" of a condition which would never have manifested over the course of a lifetime..$^{25}$

The potential application of NGS to produce extensive genomic assessments in asymptomatic populations has the potential "to yield unexpected incidental findings for nearly everyone". ${ }^{77}$ This has been coined "the incidentalome" ${ }^{\text {"77 }}$ and it has been estimated that a genome screen of an average patient would generate hundreds of false positive genetic test results. ${ }^{78}$ It should be remembered that, because the context is risk assessment, there is no gold standard at the point of testing against which to judge screening test performance. ${ }^{79}$

\section{Ethical, legal, and social issues Privacy and third-party access}

A concern within some existing screening programs, and which may be enhanced by the inclusion of personal genomic testing as part of population screening, relates to the privacy afforded to collected samples.

This issue has been widely highlighted in relation to newborn screening programs, in which samples retained for quality assurance and diagnostic purposes may also - in some jurisdictions - be made available for research. ${ }^{80}$ Such research may include clinical studies to advance knowledge regarding particular conditions - bloodspots have been used to identify if mutations associated with childhood leukemia are congenital or accumulate over time - but also for public health research such as the effect of public health policies in reducing exposure to environmental pollutants. ${ }^{81}$ It has also been proposed that bloodspots could be used for forensic purposes. $^{82,83}$ Such policies have, however, raised concerns over privacy and who should have access to samples collected - at least initially - for clinical purposes, and has motivated discussion regarding the extent to which consent given in a population screening context may cover activities beyond the primary purpose. ${ }^{82,84,85}$ Lawsuits in the US and Canada $^{86,87}$ challenging such secondary uses of biological material obtained through screening have led to changes in storage policy and, in some cases, the destruction of millions of stored samples. ${ }^{86}$ The incorporation of genomic testing within other population screening programs would likely face similar issues pertaining to initial consent for screening, but also sample retention and secondary use.

Discussions about genetics are also, almost inevitably, accompanied by concerns about implications for individual insurance eligibility. While practice varies internationally, some jurisdictions have enacted legislation in an attempt to address concerns. In the US the 2008 Genetic Information Nondiscrimination Act prohibits group health plans and health insurers denying coverage or charging higher premiums to healthy individuals based solely on genetic test results. Several other countries, such as the UK, have also taken steps to limit the use of genetic test information for the purposes of life insurance underwriting. ${ }^{88-90}$ The use of NGS in identifying incidental variants parallels traditional genetic testing, and it would be expected that patients discovering risk of serious conditions this way would face similar experiences to patients managed in traditional clinical genetics clinics.

It might be expected that similar issues would be faced by individuals receiving genomic information, irrespective of whether this is in the course of general medical care or traditional genetic testing. However, the complexity of interpreting the genomic contribution to the risk of complex disorders ${ }^{60}$ raises important empirical questions over whether such information can be used accurately for insurance underwriting purposes. Other concerns are more philosophical: they turn on questions of whether life or health insurance is seen as an essential social good, ${ }^{91-93}$ and so whether there should be universal access to insurance irrespective of prior or predicted health risks. ${ }^{94,95}$ 
To date, the empirical data regarding genetic testing and insurance discrimination suggest that concerns have been overstated.$^{20}$ In Canada, a recent policy brief noted that the empirical evidence is equivocal regarding the levels of reported genetic discrimination, and it is unclear whether reported cases of discrimination could be attributed to genetic testing per se or to family history. Moreover, it noted a lack of clarity whether reported cases represented perceived as distinct to actual discrimination. A 2013 systematic review on this topic concluded that, while there may be individual cases of genetic discrimination, existing research was not sufficiently robust to establish the prevalence or impact of discriminatory practices. ${ }^{96}$

As for personalized (stratified) screening, it might be argued that more accurate risk assessment would have no net effect at a population level, and might in fact produce net avoidance of insurance concerns if more individuals were correctly classified as lower risk than occurs with standard age-based approaches.

\section{Psychosocial effects}

There is an extensive literature on psychosocial aspects related to disclosing personal genetic risk to individuals, conducted mostly in the context of traditional clinical genetics, ${ }^{97-99}$ with exploration of the impact of NGS technologies still at an early phase.

The evidence consistently suggests that genetic testing accompanied by pre-test genetic counseling is not associated with excess psychosocial risks in general, but some individuals do experience unduly high levels of adverse psychosocial outcomes. ${ }^{99}$ Systematic reviews have concluded that the individuals most at risk of psychological morbidity are those with higher pre-test levels of anxiety or depression. ${ }^{98}$ It is plausible that the low rate of psychological morbidity associated with genetic testing is due to some extent to the role played by genetic counselors in identifying patients for whom genetic testing may cause undue harm, and helping such individuals make informed decisions to decline testing. If so, there may be concerns about harms created by offering genetic profiling as part of regular population screening without specialist genetic counseling, or seeking out additional, unexpected genetic risks in patients consenting to WGS/WES (presumably for a serious medical situation). The earliest emerging studies in the era of NGS are in the field of direct-to-consumer genetic testing, in which consumers seek out personal genetic information, often from curiosity as much as any health concern. ${ }^{36,100,101}$ While such studies provide only indirect evidence relevant to the present discussion, they appear to indicate no evidence of excess post-test distress or anxiety. ${ }^{102}$

Conversely, it has also been argued that knowledge of personal health risks arising from genetic predisposition can act as a motivator for positive behavior change. ${ }^{103}$ The evidence from studies conducted in individuals receiving standard clinical genetic testing tends to refute this. ${ }^{97,104,105}$ It is unclear whether these findings can be extrapolated to personalized screening approaches, and it has been argued that those who actively seek out personal risk information (eg, by buying direct-to-consumer test kits) may in fact be more likely than the general population to take action as a result. This area of enquiry is in its infancy, but the few studies available do not yet provide evidence to support this argument. ${ }^{102,106}$

\section{Implications for policy Need for policy oriented research}

The tremendous enthusiasm for the "genetics revolution" in health care ${ }^{107}$ risks driving the dissemination of genetic approaches into practice without evidence of clinical validity or usefulness. The extensive reporting of genomic discovery research massively overshadows the small published literature directed toward application in practice. Evidence-based policy requires evaluations of clinical validity and utility of emerging applications; implementation research to support the integration of potentially useful applications into practice; and studies of the actual impact of genomic applications on health outcomes and impact on health systems. ${ }^{108}$ Interrogating the "HuGE Navigator" 109 (a continuously updated knowledge resource on human genome research) for studies published between 2009 and 2013, it appears that only around $1 \%$ of articles address these policy-oriented questions (see http://64.29.163.162:8080/HuGENavigator/home.do). Over this 5- year period, more than 49,000 scientific articles on human genomics were published, of which only 519 were clinical trials, and 52 were reviews designed to inform clinical policy. Studies of gene discovery or gene-disease association are the foundation for developing novel genome-based tests but offer no evidence to clarify validity or utility in actual health care settings.

\section{Role of public health}

Public health experts are well placed to apply standard evaluation frameworks, including the World Health Organization (WHO) criteria for screening, ${ }^{110}$ to emerging genetic screening tests, and to encourage research on clinical and public health utility, and economic evaluations. ${ }^{20}$ The WHO criteria remain applicable even when the test is genome based ${ }^{27}$ (Table 3), 
although further complexities need to be taken into account such as concern about insurance or employment screening, and the possibility that lowering age thresholds because of genetic risk may lead to consideration of screening minors. ${ }^{24}$

However, engaging the public health profession in reviewing and evaluating genomic screening applications may require a change in culture. Some public health practitioners may disregard genetics as not only irrelevant to population-based screening programs, indeed as quite opposite in philosophy. ${ }^{20}$ Although the evidence base is currently inadequate to support the widespread implementation of genetic approaches to screening, the work of several groups suggests that this cannot be discounted as a possible future direction. ${ }^{111-113}$ Public health professionals are trained to take a population perspective, and to take an evidence-based approach to considering new health interventions. If emerging genetic applications are mistakenly discounted as irrelevant in the population perspective, there is a risk of delaying

Table 3 Principles of population screening as applied to genetic susceptibility to disease

Public health assessment

The disease or condition should be an important public health burden to the target population in terms of illness, disability, and death.

The prevalence of the genetic trait in the target population and the burden of disease attributable to it should be known.

The natural history of the condition, from susceptibility to latent disease to overt disease, should be adequately understood.

\section{Evaluation of tests and interventions}

Data should be available on the positive and negative predictive values of test with respect to a disease or condition in the target population.

The safety and effectiveness of the test and accompanying interventions should be established.

\section{Policy development and screening implementation}

Consensus regarding the appropriateness of screening and interventions for people with positive and negative test results should be based on scientific evidence.

Screening should be acceptable to the target population.

Facilities should be available for adequate surveillance, prevention, treatment, education, counseling, and social support.

Screening should be a continual process, including pilot programs, evaluation of laboratory quality and health services, evaluation of the effect of screening, and provisions for changes on the basis of new evidence.

The cost effectiveness of screening should be established.

Screening and interventions should be accessible to the target population.

There should be safeguards to ensure that informed consent is obtained and the privacy of those tested is respected, that there is no coercion or manipulation, and that those tested are protected against stigmatization and discrimination.

Note: From N Engl J Med. Khoury MJ, McCabe LL, McCabe ER. Population screening in the age of genomics medicine. 2003;348(I):50-58. Copyright $\odot 2003$ Massachusetts Medical Society. Reprinted with permission from Massachusetts Medical Society. the development, evaluation, and practical implementation of potentially beneficial approaches which could make a meaningful impact on population health.

\section{Organization of services}

Until relatively recently, in almost all health systems, genetic tests could be ordered only by geneticists, or selected specialists such as oncologists managing patients with familial cancer syndromes. This gatekeeping role is increasingly challenged as selected genetic tests are incrementally incorporated into laboratory requisition forms for use by specialists and primary care physicians. The potential inclusion of personal genomics within population screening will likely challenge this gatekeeping role further.

As genetics becomes integrated into mainstream medicine, as genetic tests are used in screening in "general" populations, and as testing becomes less targeted, it is inevitable that physicians will not always find it straightforward to interpret individual genomic test results. Close cooperation between primary care and specialist services may need to be intensified, but the model of genetic counseling as a requirement before testing ${ }^{20,24}$ would be unsustainable for incorporation into population screening programs.

\section{Professional education}

Most studies indicate that, irrespective of who orders a genetic test in the first place, patients look to primary care physicians to offer advice and be ready to use genetic information in their care. ${ }^{111,114,115}$ Many studies have shown that primary care health professionals are positively disposed toward using genomics applications in their routine practice, and agree that counseling patients about health and disease risks is consistent with their continuing care role. ${ }^{114,116-122}$ Although personal genomics should be well-suited to integration in discussions of health risks, ${ }^{115}$ many studies indicate that practitioners tend to lack confidence in their knowledge and skills, and seek practical interventions to support their efforts. ${ }^{119,123,124}$ The last two decades have seen a shift in educational approaches away from a simple "knowledge deficit" approach to targeting specialty-specific genetic competencies. ${ }^{17,125,126}$ This has matched the development of more multifaceted and sophisticated approaches to support the use of genetics which address the complexities of real life practice. ${ }^{114,127,128}$

\section{Informed decision making}

Surveys repeatedly suggest that members of the general population are interested in genetics ${ }^{129-132}$ and would consider 
genetic testing for themselves and family members. ${ }^{129,133-137}$ However, genuinely informed decision making about seeking or allowing genetic information in systematic or opportunistic screening demands a deeper appreciation of personal implications, including the possibility of receiving results which have unclear health significance; individuals need to be prepared for unexpected impact on their emotional state, family issues, access of (potential) employers and insurance companies to risk information, etc. In a clinical context, informed decision making can be supported by evidencebased decision aids ${ }^{138}$ and by providers who themselves are confident in their own understanding of genetics. However, if and when genetically-based risk stratification becomes more widespread, there is no guarantee that such a personal clinical model will apply. A thoughtful approach to public educational needs to support general literacy about genomics in health care would be desirable as a foundation for well-informed use of genetic information in population health, health care, and non-medical aspects of life. ${ }^{128}$

\section{Conclusion}

Personalized medicine and personal genomics have been described as paradigm-shifting technologies in medicine, ${ }^{139}$ although their pace of implementation may perhaps be better described as a slow revolution in health care. There are significant challenges in moving from traditional genetics, with its focus on monogenic disorders with significant implications for health of a very small proportion of the population, to the development of genetic profiling approaches which are useful for screening, risk assessment, disease prevention, and health promotion. The idea of personalized medicine as fully individualized medicine has still to be realized, and is likely unrealistic. ${ }^{140}$ However, the application of genetics in stratifying screening approaches, with potential for real health benefit (and better use of health care resources) is realistic and perhaps in reach within the next few years.

All new technologies are propelled into practice by their champions and enthusiasts, and the drivers behind personalized medicine include major funding bodies, large health care organizations, and even national governments. However, careful evaluation of health benefits achievable in practice, acknowledgment of the need to identify and quantify potential harms, and the economic implications are as important in personalized medicine as any other area of health care. It is particularly important that public health experts themselves embrace their role in this, and engage positively in framing the research agenda from a population perspective.
In addition the assessments of technologies, approaches to public and professional education will need to be developed. These will need to support general literacy about genomics in health care and should be a foundation for the well-informed use of genetic information in population health, and health care more generally.

\section{Disclosure}

The authors report no conflicts of interest in this work.

\section{References}

1. Phimister EG, Feero WG, Guttmacher AE. Realizing genomic medicine. N Engl J Med. 2012;366(8):757-759.

2. Ashley EA, Butte AJ, Wheeler MT, et al. Clinical assessment incorporating a personal genome. Lancet. 2010;375(9725):1525-1535.

3. Shahmirzadi L, Chao EC, Palmaer E, Parra MC, Tang S, Gonzalez KD. Patient decisions for disclosure of secondary findings among the first 200 individuals undergoing clinical diagnostic exome sequencing. Genet Med. 2014;16(5):395-399.

4. Jacob HJ, Abrams K, Bick DP, et al. Genomics in clinical practice: Lessons from the front lines. Sci Transl Med. 2013;5(194):194cm5.

5. Worthey EA, Mayer AN, Syverson GD, et al. Making a definitive diagnosis: successful clinical application of whole exome sequencing in a child with intractable inflammatory bowel disease. Genet Med. 2011;13(3):255-262.

6. Saunders CJ, Miller NA, Soden SE, et al. Rapid whole-genome sequencing for genetic disease diagnosis in neonatal intensive care units. Sci Transl Med. 2012;4(154):154ra135.

7. van El CG, Cornel MC, on behalf of the ESHG Public and Professional Policy Committee. Genetic testing and common disorders in a public health framework. Eur J Hum Genet. 2011;19:S1-S5.

8. Martin HC, Kim GE, Pagnamenta AT, et al. Clinical whole-genome sequencing in severe early-onset epilepsy reveals new genes and improves molecular diagnosis. Hum Mol Genet. 2014;23(12):3200-3211.

9. National Institutes of Health [homepage on the Internet]. NIH program explores the use of genomic sequencing in newborn healthcare; 2013. Available from: http://www.nih.gov/news/health/sep2013/nhgri-04. htm. Accessed July 13, 2014.

10. Genomics England [homepage on the Internet]. Genomics England; 2014. Available from: http://www.genomicsengland.co.uk/. Accessed July 13, 2014.

11. National Library of Medicine [homepage on the Internet]. Personalized medicine; 2014. Available from: http://ghr.nlm.nih.gov/ glossary=personalizedmedicine. Accessed August 18, 2014.

12. Lotta LA. Genome-wide association studies in atherothrombosis. Eur J Intern Med. 2010;21(2):74-78.

13. Pogribny IP. Epigenetic events in tumorigenesis: Putting the pieces together. Exp Oncol. 2010;32(3):132-136.

14. Moore AF, Florez JC. Genetic susceptibility to type 2 diabetes and implications for antidiabetic therapy. Annu Rev Med. 2008;59:95-111.

15. Distefano JK, Taverna DM. Technological issues and experimental design of gene association studies. Methods Mol Biol. 2011;700:3-16.

16. Capriotti E, Altman RB, Bromberg Y. Collective judgment predicts disease-associated single nucleotide variants. BMC Genomics. 2013; 14 Supp1 3:S2.

17. Stolerman ES, Florez JC. Genomics of type 2 diabetes mellitus: implications for the clinician. Nat Rev Endocrinol. 2009;5(8):429-436.

18. Bunnik EM, Schermer MH, Janssens AC. Personal genome testing: test characteristics to clarify the discourse on ethical, legal and societal issues. BMC Med Ethics. 2011;12:11.

19. Auffray C, Caulfield T, Khoury MJ, Lupski JR, Schwab M, Veenstra T. Genome Medicine: past, present and future. Genome Med. 2011;3(1):6. 
20. Becker F, van El CG, Ibarreta D, et al. Genetic testing and common disorders in a public health framework: how to assess relevance and possibilities. Background Document to the ESHG recommendations on genetic testing and common disorders. Eur J Hum Genet. 2011; 19 Suppl 1:S6-S44.

21. Burke W, Psaty BM. Personalized medicine in the era of genomics. JAMA. 2007;298(14):1682-1684.

22. Pashayan N, Pharoah P. Population-based screening in the era of genomics. Per Med. 2012;9(4):451-455.

23. Cleeren E, Van der Heyden J, Brand A, Van Oyen H. Public health in the genomic era: will public health genomics contribute to major changes in the prevention of common diseases? Arch Public Health. 2011;69(1):8.

24. Chowdhury S, Dent T, Pashayan N, et al. Incorporating genomics into breast and prostate cancer screening: assessing the implications. Genet Med. 2013;15(6):423-432.

25. Burke W, Tarini B, Press NA, Evans JP. Genetic screening. Epidemiol Rev. 2011;33(1):148-164.

26. Beskow LM, Burke W. Offering individual genetic research results: Context matters. Sci Transl Med. 2010;2(38):38cm20.

27. Khoury MJ, McCabe LL, McCabe ER. Population screening in the age of genomics medicine. N Engl J Med. 2003;348(1):50-58.

28. Marks D, Wonderling D, Thorogood M, Lambert H, Humphries SE, Neil HA. Cost effectiveness analysis of different approaches of screening for familial hypercholesterolaemia. BMJ. 2002;324(7349):1303.

29. Smith GD, Ebrahim S, Lewis S, Hansell AL, Palmer LJ, Burton PR. Genetic epidemiology and public health: hope, hype, and future prospects. Lancet. 2005;366(9495):1484-1498.

30. King MC, Levy-Lahad E, Lahad A. Population-based screening for BRCA1 and BRCA2: 2014 Lasker Award. JAMA. 2014;312(11): 1091-1092.

31. Robertson L, Hanson H, Seal S, et al. BRCA1 testing should be offered to individuals with triple-negative breast cancer diagnosed below 50 years. Br J Cancer. 2012;106(6):1234-1238.

32. Qureshi N, Wilson B, Santaguida P, et al. Family history and improving health. Evid Rep Technol Assess (Full Rep). 2009;(186):1-135.

33. Pyeritz RE. The family history: the first genetic test, and still useful after all those years? Genet Med. 2012;14(1):3-9.

34. McGuire AL, Cho MK, McGuire SE, Caulfield T. Medicine. The future of personal genomics. Science. 2007;317(5845):1687.

35. Caulfield T. Direct-to-consumer genetics and health policy: a worst-case scenario? Am J Bioeth. 2009;9(6-7):48-50.

36. Caulfield T, Ries NM, Ray PN, Shuman C, Wilson B. Direct-toconsumer genetic testing: good, bad or benign? Clin Genet. 2010;77(2): 101-105.

37. Hogarth S, Javitt G, Melzer D. The current landscape for direct-toconsumer genetic testing: legal, ethical, and policy issues. Annu Rev Genomics Hum Genet. 2008;9:161-182.

38. Janssens AC, van Duijn CM. Genome-based prediction of common diseases: advances and prospects. Hum Mol Genet. 2008;17(R2): R166-R173.

39. Pashayan N, Hall A, Chowdhury S, Dent T, Pharoah PD, Burton H. Public health genomics and personalized prevention: lessons from the COGS project. J Intern Med. 2013;274(5):451-456.

40. Fredholm H, Eaker S, Frisell J, Holmberg L, Fredriksson I, Lindman H. Breast cancer in young women: poor survival despite intensive treatment. PLos One. 2009;4(11):e7695.

41. Hawken SJ, Greenwood CM, Hudson TJ, et al. The utility and predictive value of combinations of low penetrance genes for screening and risk prediction of colorectal cancer. Hum Genet. 2010;128(1):89-101.

42. Dunlop MG, Tenesa A, Farrington SM, et al. Cumulative impact of common genetic variants and other risk factors on colorectal cancer risk in 42103 individuals. Gut. 2013;62(6):871-881.

43. Janssens AC, Pardo MC, Steyerberg EW, van Duijn CM. Revisiting the clinical validity of multiplex genetic testing in complex diseases. Am J Hum Genet. 2004;74(3):585-588.
44. Khoury MJ, Yang Q, Gwinn M, Little J, Dana Flanders W. An epidemiologic assessment of genomic profiling for measuring susceptibility to common diseases and targeting interventions. Genet Med. 2004;6(1): 38-47.

45. Pasche B, Absher D. Whole-genome sequencing: a step closer to personalized medicine. JAMA. 2011;305(15):1596-1597.

46. Biesecker LG. Opportunities and challenges for the integration of massively parallel genomic sequencing into clinical practice: lessons from the ClinSeq project. Genet Med. 2012;14(4):393-398.

47. Macera MJ, Sobrino A, Levy B, et al. Prenatal diagnosis of chromothripsis, with nine breaks characterized by karyotyping, FISH, microarray and whole-genome sequencing. Prenat Diagn. Epub July 9, 2014.

48. Yurkiewicz IR, Korf BR, Lehmann LS. Prenatal whole-genome sequencing - Is the quest to know a fetus's future ethical? $N$ Engl J Med. 2014;370(3):195-197.

49. Green RC, Berg JS, Grody WW, et al. ACMG recommendations for reporting of incidental findings in clinical exome and genome sequencing. Genet Med. 2013;15(7):565-574.

50. Johnston JJ, Rubinstein WS, Facio FM, et al. Secondary variants in individuals undergoing exome sequencing: screening of 572 individuals identifies high-penetrance mutations in cancer-susceptibility genes. Am J Hum Genet. 2012;91(1):97-108.

51. Costain G, Bassett AS. Incomplete knowledge of the clinical context as a barrier to interpreting incidental genetic research findings. Am J Bioeth. 2013;13(2):58-60.

52. Burke W, Matheny Antommaria AH, Bennett R, et al. Recommendations for returning genomic incidental findings? We need to talk! Genet Med. 2013;15(11):854-859.

53. Burke W, Laberge AM, Press N. Debating clinical utility. Public Health Genomics. 2010;13(4):215-223.

54. Grosse SD, Khoury MJ. What is the clinical utility of genetic testing? Genet Med. 2006;8(7):448-450.

55. Veenstra DL, Roth JA, Garrison LP Jr, Ramsey SD, Burke W. A formal risk-benefit framework for genomic tests: Facilitating the appropriate translation of genomics into clinical practice. Genet Med. 2010;12(11):686-693.

56. Teutsch SM, Bradley LA, Palomaki GE, et al. The Evaluation of Genomic Applications in Practice and Prevention (EGAPP) Initiative: methods of the EGAPP Working Group. Genet Med. 2009;11(1):3-14.

57. Secretary's Advisory Committee on Genetic Testing. Enhancing the Oversight of Genetic Tests: Recommendations of the SACGT. Bethesda, Maryland: National Institutes of Health; 2000.

58. Korf BR, Rehm HL. New approaches to molecular diagnosis. JAMA. 2013;309(14):1511-1521.

59. 1000 Genomes Project Consortium, Abecasis GR, Altshuler D, et al. A map of human genome variation from population-scale sequencing. Nature. 2010;467(7319):1061-1073.

60. Feero WG. Clinical application of whole-genome sequencing. Proceed with care. JAMA. 2014;311(10):1017-1019.

61. Dewey FE, Grove ME, Pan C, et al. Clinical Interpretation and Implications of Whole-Genome Sequencing. JAMA. 2014;311(10):1035-1045.

62. Gibson G. Rare and common variants: twenty arguments. Nat Rev Genet. 2011;13(2):135-145.

63. Frazer KA, Murray SS, Schork NJ, Topol EJ. Human genetic variation and its contribution to complex traits. Nat Rev Genet. 2009;10(4): 241-251.

64. Bodmer W, Bonilla C. Common and rare variants in multifactorial susceptibility to common diseases. Nat Genet. 2008;40(6): 695-701.

65. Gylfe AE, Katainen R, Kondelin J, et al. Eleven candidate susceptibility genes for common familial colorectal cancer. PLoS Genetics. 2013;9(10):e1003876

66. Evaluation of Genomic Applications in Practice and Prevention [homepage on the Internet]. EGAPP Topics Under Review; 2010. Available from: http://www.egappreviews.org/workingrp/topics_ review.htm. Accessed October 31, 2014. 
67. Evaluation of Genomic Applications in Practice and Prevention [homepage on the Internet]. EGAPP Working Group Recommendations; 2013. Available from: http://www.egappreviews.org/recommendations/ index.htm. Accessed October 31, 2014.

68. Evaluation of Genomic Applications in Practice and Prevention (EGAPP) Working Group. Recommendations from the EGAPP Working Group: does genomic profiling to assess type 2 diabetes risk improve health outcomes? Genet Med. 2013;15(8): 612-617.

69. Dotson WD, Douglas MP, Kolor K, et al. Prioritizing genomic applications for action by level of evidence: a horizon-scanning method. Clin Pharmacol Ther. 2014;95(4):394-402.

70. Centers for Disease Control and Prevention [homepage on the Internet]. Genomic Tests and Family History by Levels of Evidence; 2014 Available from: http://www.cdc.gov/genomics/gtesting/tier.htm. Accessed October 31, 2014.

71. Stenson PD, Mort M, Ball EV, Shaw K, Phillips A, Cooper DN. The Human Gene Mutation Database: building a comprehensive mutation repository for clinical and molecular genetics, diagnostic testing and personalized genomic medicine. Hum Genet. 2014;133(1):1-9.

72. The Human Gene Mutation Database [homepage on the Internet]. Available from: http://www.hgmd.org/. Accessed July 12, 2014.

73. Bell CJ, Dinwiddie DL, Miller NA, et al. Carrier testing for severe childhood recessive diseases by next-generation sequencing. Sci Transl Med. 2011;3(65):65ra4.

74. Dorschner MO, Amendola LM, Turner EH, et al. Actionable, pathogenic incidental findings in 1,000 participants' exomes. Am J Hum Genet. 2013;93(4):631-640

75. Wilcken B, Wiley V, Hammond J, Carpenter K. Screening newborns for inborn errors of metabolism by tandem mass spectrometry. $N$ Engl J Med. 2003;348(23):2304-2312.

76. Potter BK, Chakraborty P, Kronick JB, et al. Achieving the "triple aim" for inborn errors of metabolism: a review of challenges to outcomes research and presentation of a new practice-based evidence framework. Genet Med. 2013;15(6):415-422.

77. Kohane IS, Masys DR, Altman RB. The incidentalome: a threat to genomic medicine. JAMA. 2006;196(2):212-215.

78. Kohane IS, Hsing M, Kong SW. Taxonomizing, sizing, and overcoming the incidentalome. Genet Med. 2012;14(4):399-404.

79. Wright CF, Kroese M. Evaluation of genetic tests for susceptibility to common complex diseases: why, when and how? Hum Genet. 2010;127(2):125-134.

80. Botkin JR, Goldenberg AJ, Rothwell E, Anderson RA, Lewis MH. Retention and research use of residual newborn screening bloodspots. Pediatrics. 2012;131(1):120-127.

81. Spliethoff HM, Tao L, Shaver SM, et al. Use of newborn screening program blood spots for exposure assessment: declining levels of perfluorinated compounds in New York State infants. Environ Sci Technol. 2008;42(14):5361-5367

82. Couzin-Frankel J. Science gold mine, ethical minefield. Science. 2009;324(5924):166-168.

83. Douglas C, van El C, Radstake M, van Teeffelen S, Cornel MC. The politics of representation in the governance of emergent 'secondary use' biobanks: the case of dried blood spot cards in the Netherlands. Studies in Ethics Law and Technology. 2012;6(1): article 4.

84. Muchamore I, Morphett L, Barlow-Stewart K. Exploring existing and deliberated community perspectives of newborn screening: informing the development of state and national policy standards in newborn screening and the use of dried blood spots. Aust New Zealand Health Policy. 2006;3:14.

85. Bombard Y, Miller FA, Hayeems RZ, et al. Citizens' values regarding research with stored samples from newborn screening in Canada. Pediatrics. 2012;129(2):239-247.

86. Lewis MH, Scheurer ME, Green RC, McGuire AL. Research results: Preserving newborn blood samples. Sci Transl Med. 2012;4(159): $159 \mathrm{~cm} 12$.
87. The Globe and Mail [homepage on the Internet]. Armstrong J. Storage of newborns' blood samples raises privacy concerns; 2010. Available from: http://www.theglobeandmail.com/news/british-columbia/ storage-of-newborns-blood-samples-raises-privacy-concerns / article4318768/. Accessed November 12, 2014.

88. Keogh LA, Otlowski MF. Life insurance and genetic test results: a mutation carrier's fight to achieve full cover. Med J Aust. 2013;199(5):363-366.

89. Needs J. Insurance Discrimination in the UK - Life Insurance and Genetic Risk. Encyclopedia of Life Sciences. Chichester, UK: John Wiley \& Sons Ltd; 2007.

90. Thomas RG. Genetics and insurance in the United Kingdom 1995-2010: the rise and fall of "scientific" discrimination. New Genet Soc. 2012;31(2):203-222.

91. Joly Y, Braker M, Le Huynh M. Genetic discrimination in private insurance: global perspectives. New Genet Soc. 2010;29(4): 351-368.

92. Joly Y, Burton H, Knoppers BM, et al. Life insurance: genomic stratification and risk classification. Eur J Hum Genet. 2014;22(5): 575-579.

93. Liukko J. Genetic discrimination, insurance, and solidarity: an analysis of the argumentation for fair risk classification. New Genet Soc. 2010;29(4):457-475.

94. Ashcroft R. Should genetic information be disclosed to insurers: No. BMJ. 2007;334(7605):1197.

95. Van Hoyweghen I, Rebert L. Your genes in insurance: from genetic discrimination to genomic solidarity. Personalized Medicine. 2012; 9(8):871-877.

96. Joly Y, Ngueng Feze I, Simard J. Genetic discrimination and life insurance: a systematic review of the evidence. BMC Med. 2013;11:25.

97. Marteau TM, French DP, Griffin SJ, et al. Effects of communicating DNA-based disease risk estimates on risk-reducing behaviours. Cochrane Database Syst Rev. 2010(10):CD007275.

98. Broadstock M, Michie S, Marteau T. Psychological consequences of predictive genetic testing: a systematic review. Eur J Hum Genet. 2000;8(10):731-738

99. Heshka JT, Palleschi C, Howley H, Wilson B, Wells PS. A systematic review of perceived risks, psychological and behavioral impacts of genetic testing. Genet Med. 2008;10(1):19-32.

100. McGuire AL, Diaz CM, Wang T, Hilsenbeck SG. Social networkers' attitudes toward direct-to-consumer personal genome testing. Am J Bioeth. 2009;9(6-7):3-10.

101. Facio FM, Brooks S, Loewenstein J, Green S, Biesecker LG, Biesecker BB. Motivators for participation in a whole-genome sequencing study: implications for translational genomics research. Eur J Hum Genet. 2011;19(12):1213-1217.

102. Bloss CS, Wineinger NE, Darst BF, Schork NJ, Topol EJ. Impact of direct-to-consumer genomic testing at long term follow-up. $\mathrm{J} \mathrm{Med}$ Genet. 2013;50(6):393-400.

103. Bloss CS, Madlensky L, Schork NJ, Topol EJ. Genomic information as a behavioral health intervention: can it work? Per Med. 2011;8(6): 659-667.

104. McBride CM, Bowen D, Brody LC, et al. Future health applications of genomics: priorities for communication, behavioral, and social sciences research. Am J Prev Med. 2010;38(5):556-565.

105. Caulfield T, Evans J, McGuire A, et al. Reflections on the cost of "lowcost" whole genome sequencing: Framing the health policy debate. PLoS Biol. 2013;11(11):e1001699.

106. O'Daniel JM, Haga SB, Willard HF. Considerations for the impact of personal genome information: a study of genomic profiling among genetics and genomics professionals. J Genet Couns. 2010;19(4): 387-401.

107. Collins FS. Shattuck lecture - Medical and societal consequences of the human genome project. N Engl J Med. 1999;341(1):28-37.

108. Khoury MJ. Dealing with the evidence dilemma in genomics and personalized medicine. Clin Pharmacol Ther. 2010;87(6):635-638. 
109. Yu W, Gwinn M, Clyne M, Yesupriya A, Khoury MJ. A navigator for human genome epidemiology. Nat Genet. 2008;40(2):124-125.

110. Wilson JMG, Jungner G. Principles and practice of screening for disease. Geneva: WHO; 1968.

111. Nicholls SG, Wilson BJ, Craigie SM, et al. Public attitudes towards genomic risk profiling as a component of routine population screening. Genome. 2013;56(10):626-633.

112. Burton H, Chowdhury S, Dent T, Hall A, Pashayan N, Pharoah P. Public health implications from COGS and potential for risk stratification and screening. Nat Genet. 2013;45(4):349-351.

113. Burton H, Sagoo GS, Pharoah P, Zimmern RL. Time to revisit Geoffrey Rose: strategies for prevention in the genomic era? Ital J Public Health. 2012;9(4):e8665-8661-e8665-8669.

114. Carroll JC, Wilson BJ, Allanson J, et al. GenetiKit: a randomized controlled trial to enhance delivery of genetics services by family physicians. Fam Pract. 2011;28(6):615-623.

115. McGuire AL, Burke W. An unwelcome side effect of direct-to-consumer personal genome testing. JAMA. 2008;300(22):2669-2671.

116. Carroll JC, Brown JB, Blaine S, Glendon G, Pugh P, Medved W. Genetic susceptibility to cancer. Family physicians' experience. Can Fam Physician. 2003;49:45-52.

117. Farndon PA, Bennett C. Genetics education for health professionals: strategies and outcomes from a national initiative in the United Kingdom. J Genet Couns. 2008;17(2):161-169.

118. Trinidad SB, Fryer-Edwards K, Crest A, Kyler P, Lloyd-Puryear MA, Burke W. Educational needs in genetic medicine: primary care perspectives. Community Genet. 2008;11(3):160-165.

119. Bonter K, Desjardins C, Currier N, Pun J, Ashbury FD. Personalised medicine in Canada: a survey of adoption and practice in oncology, cardiology and family medicine. BMJ Open. 2011;1(1):e000110.

120. Haga SB, Carrig MM, O'Daniel JM, et al. Genomic risk profiling: attitudes and use in personal and clinical care of primary care physicians who offer risk profiling. J Gen Intern Med. 2011;26(8):834-840.

121. Mainous AG 3rd, Johnson SP, Chirina S, Baker R. Academic family physicians' perception of genetic testing an integration into practice: A CERA study. Fam Med. 2013;45(4):257-262.

122. Carroll JC, Rideout AL, Wilson BJ, et al. Genetic education for primary care providers. Improving attitudes, knowledge, and confidence. Can Fam Physician. 2009;55(12):e92-e99.

123. Bottorff JL, Blaine S, Carroll JC, et al. The educational needs and professional roles of Canadian physicians and nurses regarding genetic testing and adult onset hereditary disease. Community Genet. 2005;8(2):80-87.

124. Wilson BJ, Torrance N, Mollison J, et al. Improving the referral process for familial breast cancer genetic counselling: findings of three randomised controlled trials of two interventions. Health Technol Assess. 2005;9(3):1-126.

125. National Coalition for Health Professional Education in Genetics (NCHPEG). Core Competencies in Genetics for Health Professionals. Lutherville, MD: National Coalition for Health Professional Education in Genetics; 2007.
126. Consensus Panel on Genetic/Genomic Nursing Competencies. Essentials of Genetic and Genomic Nursing: Competencies, Curricula Guidelines, and Outcome Indicators. Silver Spring, MD: American Nurses Association; 2009.

127. Blaine SM, Carroll JC, Rideout AL, et al. Interactive genetic counseling role-play: a novel educational strategy for family physicians. J Genet Couns. 2008;17(2):189-195.

128. Korf BR. Genetics and genomics education: the next generation. Genet Med. 2011;13(3):201-202.

129. Condit C. What is 'public opinion' about genetics? Nat Rev Genet. 2001;2(10):811-815.

130. Condit CM. Public attitudes and beliefs about genetics. Annu Rev Genomics Hum Genet. 2010;11:339-359.

131. Etchegary H, Dicks E, Green J, Hodgkinson K, Pullman D, Parfrey P. Interest in newborn genetic testing: a survey of prospective parents and the general public. Genet Test Mol Biomarkers. 2012;16(5): 353-358

132. Etchegary H, Green J, Parfrey P, Street C, Pullman D. Community engagement with genetics: public perceptions and expectations about genetics research. Health Expect. Epub August 23, 2013.

133. Michie S, Drake H, Bobrow M, Marteau T. A comparison of public and professionals' attitudes towards genetic developments. Public Understand Sci. 1995;4(3):243-253.

134. Anderson AE, Flores KG, Boonyasiriwat $\mathrm{W}$, et al. Interest and informational preferences regarding genomic testing for modest increases in colorectal cancer risk. Public Health Genomics. 2014;17(1):48-60.

135. Andrykowski MA, Munn RK, Studts JL. Interest in learning of personal genetic risk for cancer: a general population survey. Prev Med. 1996;25(5):527-536.

136. Kinney AY, Choi YA, DeVillis B, Kobetz E, Millikan RC, Sandler RS. Interest in genetic testing among first-degree relatives of colorectal cancer patients. Am J Prev Med. 2000;18(3):249-252.

137. Ramsey SD, Wilson S, Spencer A, Geidzinska A, Newcomb P. Attitudes towards genetic screening for predisposition to colon cancer among cancer patients, their relatives and members of the community. Results of focus group interviews. Community Genet. 2003;6(1):29-36.

138. Stacey D, Légaré F, Col NF, et al. Decision aids for people facing health treatment or screening decisions. Cochrane Database Syst Rev. 2014;1:CD001431.

139. Manyika J, Chui M, Bughin J, Dobbs R, Bisson P, Mars A. Disruptive Technologies: Advances that will Transform Life, Business, and the Global Economy. McKinsey Global Institute; 2013.

140. Nicholls SG, Wilson BJ, Castle D, Etchegary H, Carroll JC. Personalized medicine and genome-based treatments: why personalized medicine \# individualized treatments. Clin Ethics. 2014;9(4):135-144.
Risk Management and Healthcare Policy

\section{Publish your work in this journal}

Risk Management and Healthcare Policy is an international, peerreviewed, open access journal focusing on all aspects of public health, policy, and preventative measures to promote good health and improve morbidity and mortality in the population. The journal welcomes submitted papers covering original research, basic science, clinical \& epidemio-
Dovepress

logical studies, reviews and evaluations, guidelines, expert opinion and commentary, case reports and extended reports. The manuscript management system is completely online and includes a very quick and fair peerreview system, which is all easy to use. Visit http://www.dovepress.com/ testimonials.php to read real quotes from published authors. 